\title{
Muhasebe ve Denetim Bölümü Öğrencilerinin Sosyal Medya ve Kişisel Gelişim İle İlgili Görüşleri: Bilecik Şeyh Edebali Üniversitesi, Uygulamalı Bilimler Yüksekokulu Örneği
}

\author{
Berna DEMIR ${ }^{l} \&$ Ayşenur ATALAY $Y^{2}$ \& Melike ÖZTÜRK ${ }^{3}$
}

Öz

Bu çalışma, Muhasebe ve Denetim Bölümü öğrencilerinin sosyal medya ve kişisel gelişimle ilgili görüşlerini ve çabalarını ortaya koymak amacıyla yapılmıştır. Çalışma kapsamında bu bölümde okuyan öğrencilere anket uygulanmıştır. Yapılan çalışmada, öğrencilerin çoğunun sosyal medya hesabı olarak ilk sırada Instagram'ı kullandıkları görülmüştür. Sosyal medyada iletişimi Whatsapp ile kurmaktadırlar. Sosyal medyayı daha çok bilgi edinme ve bilgi paylaşımı için kullanmaktadırlar. Üniversite yaşamının kişisel gelişimlerine önemli katkılar sağladığını düşünmektedirler. Öğrenciler genelde kişisel gelişimin kendilerine olan güvenlerinin artması için önemli olduğunu düşünmektedirler. Okulda düzenlenen mesleki seminerlerin ve bölüm derslerinin uygulama ağırlıklı olmasının kişisel gelişimlerine önemli katkılar sağladığını düşünenleri sayısı fazladır. Kitap okumanın kişisel gelişim için çok önemli olduğunu düşünmektedirler. Genelde sosyal sorumluluk kapsamında etkinliklere katılmaktadırlar. Alan ile ilgili güncel gelişmeleri takip etmekte, yabancı dillerini geliştirmek için çabalamaktadırlar. Ancak muhasebe mesleğini ilgilendiren sempozyum, panel gibi etkinlikleri ve dergileri yakından takip edenlerin sayısı azdır.

Anahtar Kelimeler: Muhasebe ve Denetim Bölümü, öğrenciler, sosyal medya, kişisel gelişim.

The opinions On Social Media And Personal Development Of The Students Of Accounting And Auditing Programme: Bilecik Şeyh Edebali University, School Of Applied Sciences Sample

\begin{abstract}
This study was carried out to reveal the Accounting and Auditing Programme students' opinions and efforts on social media and personal development. A questionnaire was applied to the students studying in this section. In the study, it was seen that most of the students used Instagram as the first social media account. They communicate with social media on Whatsapp. They use social media for more information and information sharing. They think that university life makes important contributions to personal development. Students generally think that personal development is important for their self-confidence. The number of those who think that vocational seminars and departmental courses that are organized in the school provide significant contributions to their personal development. They think reading books is very important for personal development. They generally participate in social responsibility activities. They follow current developments in the field and strive to improve their foreign languages. However, the number of those who closely follow the activities such as symposiums, panels and magazines concerning the accounting profession are few.
\end{abstract}

Keywords: Accounting and Auditing Programme, students, social media, personal development.

1 Doç. Dr., Bilecik Şeyh Edebali Üniversitesi, Uygulamalı Bilimler Yüksekokulu, Muhasebe ve Denetim Bölümü, berna.demir@bilecik.edu.tr

${ }^{2}$ Tezli Yüksek Lisans Öğrencisi, Bilecik Şeyh Edebali Üniversitesi, Sosyal Bilimler Enstitüsü, Muhasebe ve Denetimi Bölümü, aysenurratalay@gmail.com

${ }^{3}$ Tezli Yüksek Lisans Öğrencisi, Bilecik Şeyh Edebali Üniversitesi, Sosyal Bilimler Enstitüsü, Uygulamalı Bilimler Yüksekokulu, Muhasebe ve Denetim Bölümü, melikeoztturk@gmail.com 


\section{Giriş}

İletişim olanaklarının, yaşam biçiminin ve teknolojinin değişimi ve gelişimi ile birlikte, bilgi edinme, kişisel gelişim süreci ve içeriği değişime uğramış, farklı bir boyut almıştır. Özellikle medyanın biçim değiştirmesi, yeni medya ile doğan sosyal medya ortamı, bilginin çeşitlenmesinde, bilginin yaygınlaşmasında, bilginin biçiminde, bilgiye ulaşılmasında ve bilginin içselleştirilmesinde belirleyici bir faktör rolünü üstlenmiştir. Artık bireyler siyasi, sosyal, kültürel, ekonomik, sanatsal bilgileri ve gündemi İnternet ve sosyal medyadan rahatlıkla edinmektedir (Kamiloğlu vd. 2014: 132).

Sosyal medya zaman ve mekân sınırlaması olmadan (mobil tabanlı), paylaşımın, tartışmanın esas olduğu bir insanî iletişim şeklidir (Vural vd. 2010: 3351). Kendini sürekli yenileyen İnternet sosyal medya ile kendi içinde altın çağını yaşamaktadır. Bu çağ öyle bir çağdır ki insanların hayatlarına dokunmaktadır. Birçok kişi arkadaşlarıyla görüşmek, arkadaşlarının fotoğraflarına ve iletilerine bakmak, mesaj göndermek ve almak, eğlenmek, boş zamanını değerlendirmek, bilgiye erişmek, gündemi takip etmek için sosyal medyayı kullanmaktadır (Başoğlu vd. 2017: 7).

İnternet sunduğu olanaklarla geleneksel medyadan ayrılmaktadır. Televizyon ve yazılı basın gibi geleneksel iletişim kanalları görsel anlamda etkileyici olmakla birlikte, tek yönlü bir iletişim kurmaktadırlar. İnternet'in sağladığı web uygulamalarında ise iletişim kuran taraflar arasında eş zamanlı ve iki yönlü bilgi akışı sağlanmaktadır (Başoğlu vd. 2017: 7).

Kişisel gelişim veya kişisel büyüme bireysel olarak kişinin yeteneklerini, becerilerini, bilgi veya diğer niteliklerini onlar üzerine çalışarak geliştirmesi demektir. Kendini geliştirme yalnız yapılan bir olgu değil, kişinin çevresi ile ilgili karşı1ıklı etkileşimi yoluyla oluşmaktadır. Özellikle sosyal medya uygulamaları ile İnternet, bireyin sosyal çevresi ile daha sık etkileşim kurabilmesine olanak sağlamaktadır (Kamiloğlu vd. 2014: 136).

Kişisel gelişim, yetişkin benliğine sahip birey olma yolunda kişinin sahip olduğu potansiyelini, yeteneklerini ve kaynaklarını etkili biçimde kullanarak yaşam boyu gelişimidir. Kişisel gelişimin ilk adımı kendini tanımaktır. Birey inanç ve değerleri, kişilik yapısı ve sergilediği davranış tarzları, bilgi düzeyi, güçlü ve geliştirmesi gereken becerileri, zayıf yönler gibi kendiyle ilgili konularda farkındalık kazanmalıdır (Balaban vd. 2016: 3).

Üniversite yaşamı, öğrencilerin kişisel gelişimi için önemli bir yere sahiptir. Sadece okul başarısı değil üniversitede öğrencinin kendisini ne kadar geliştirdiği de önemlidir. $\mathrm{Bu}$ nedenle öğrenciler dersleri kadar kendilerini geliştirmeye de önem vererek bilgi, beceri ve deneyimlerini arttırmalıdırlar.

Üniversitelere bağlı Uygulamalı Bilimler Yüksekokulları bünyesinde kurulan Muhasebe ve Denetim Bölümleri'nin amacı muhasebe mesleğinde kariyer yapmak isteyen öğrencilerin müşavirlik, denetim ve maliyet muhasebesi alanlarında hem teorik açıdan, hem de uygulama açısından gerekli alt yapıyla donatılarak, hali hazırda yaşanan eğitim sonrası mesleğe uyum sorunlarını yaşamadan, iş 
hayatına atılmalarını ve sektörün talebinin karşılanmasını sağlamaktır (Kurnaz ve Gümüş, 2010: 157). Bölüm derslerinin uygulama ağırlıklı olması öğrencilerin kişisel gelişimlerine önemli katkılar sağlamaktadır.

Sosyal medya ve kişisel gelişimin üniversite gençliği üzerindeki öneminden dolayı, Uygulamalı Bilimler Yüksekokulu, Muhasebe ve Denetim Bölümü öğrencilerinin sosyal medya ve kişisel gelişim ile ilgili görüşlerini ve çabalarını ortaya koymak amacıyla bu çalışma yapılmıştır.

\section{Araştırmanın Amacı}

Bu çalışmanın amacı, Bilecik Şeyh Edebali Üniversitesi, Uygulamalı Bilimler Yüksekokulu, Muhasebe ve Denetim Bölümü öğrencilerinin sosyal medya ve kişisel gelişim ile ilgili görüşlerini ortaya koymaktır. Bu araştırmada sorgulanan ana unsurlar;

- Kullanılan sosyal medya hesapları,

- Kullanılan iletişim kanalları,

- Gündeme düşen olayı ilk nereden öğrendikleri,

- Sosyal medya ile ilgili düşünceleri,

- Kişisel gelişimi artırmanın neden önemli olduğu,

- Üniversite yaşamının kişisel gelişime katkıları,

- Kişisel gelişim ile ilgili çabalarıdır.

\section{Araştırma Yöntemi}

\subsection{Araştırma Evreni}

Araştırmanın evrenini, Bilecik Şeyh Edebali Üniversitesi, Uygulamalı Bilimler Yüksekokulu, Muhasebe ve Denetim Bölümü’nde öğrenim gören öğrenciler oluşturmaktadır. Muhasebe ve Denetim Bölümü’nde 2017-2018 öğretim y1lında kayıtlı 188 öğrenci bulunmaktadır. Aktif öğrenci sayıs1 162'dir. Anket okulda mevcut bulunan 141 öğrenciye uygulanmıştır. Anket uygulanan öğrenci sayısı aktif öğrenci sayısının \% 87'sini oluşturmaktadır. Yapılan anketlerin tamamı değerlendirilmiştir. 141 öğrencinin tamamı anketteki tüm sorulara yanıt vermiştir.

Kadın öğrencilerin sayısı 91, erkek öğrencilerin sayıs1 50'dir. Öğrenciler ağırlıklı olarak (88 öğrenci) Ticaret Lisesi’nden mezun olmuşlardır. 27 öğrenci düz liseden mezundur. Diğer öğrenciler İmam Hatip Lisesi, Kız Meslek Lisesi, Mesleki Teknik Endüstri Lisesi’nden mezundur.

Anket uygulamaya konulmadan önce, Bilecik Şeyh Edebali Üniversitesi Etik Kurulu'ndan gerekli izin ve onay alınmıştır. 


\subsection{Araştırma Yöntemi ve Verilerin Toplanması}

Araştırmada;

- Veri toplama yöntemi olarak anket yöntemi kullanılmıştır.

- "Tanımlayıcı (Betimsel) ve Bağıntısal Araştırma Modeli” kullanılmıştır.

- Anketin geçerliliğinin sınanması amacıyla literatür araştırması yapılmış, uzman kişilerden görüş alınmış ve anket uygulanmadan önce pilot çalışma yapılmıştır.

- Verilerin analizi, SPSS (Statististical Package for the Social Sciences) paket programında yapılmıştır.

- Verilerin analizinde; frekans (sayı) ve yüzde tekniklerinden yararlanılmıştır.

- Değişkenler arasındaki farklılıkları ortaya koymak amacıyla Crosstabs testi uygulanmıştır.

- Öğrencilerin sosyal medya ve kişisel gelişim ile ilgili görüşleri alınırken 3'lü Likert (3.Katılıyorum-2.Kararsızım-1.Katılmıyorum) ölçeği kullanılmıştır.

\section{Araştırma Bulguları}

\subsection{Sosyal Medya İle İlgili Görüşleri}

\subsubsection{Kullanılan Sosyal Medya Hesapları}

Ankete katılan 141 öğrencinin \%70,9’u Instagram'1 birinci sırada kullanmaktadır. Facebook ise öğrencilerin sadece \%9,9'unun ilk sırada kullandığı sosyal medya hesabıdır (Tablo 1).

Tablo 1. Kullanılan Sosyal Medya Hesapları

\begin{tabular}{|c|c|c|}
\hline Kullanılan Sosyal Medya Hesapları & Sayı & \% \\
\hline Facebook & 14 & 9,9 \\
\hline Twitter & 5 & 3,5 \\
\hline Google+ & 16 & 11,3 \\
\hline Instagram & 100 & 70,9 \\
\hline Linkedin & 1 & 0,7 \\
\hline Pinterest & 2 & 1,4 \\
\hline Diğer & 3 & 2,1 \\
\hline Toplam & $\mathbf{1 4 1}$ & $\mathbf{1 0 0}$ \\
\hline
\end{tabular}

\subsubsection{Kullanılan İletişim Kanalları}

Öğrencilerin \% 89,4'ü sosyal medyada iletişimi Whatsapp ile kurmaktadırlar. Görüldüğü üzere Whatsapp önemli bir iletişim aracıdır. İkinci sırada Facebook Messenger yer almaktadır (Tablo 2). 
Tablo 2. Kullanılan Iletişim Kanalları

\begin{tabular}{|l|c|c|}
\hline Kullanılan İletişim Kanalları & Sayı & $\mathbf{\%}$ \\
\hline Whatsapp & 126 & 89,4 \\
\hline Facebook Messenger & 12 & 8,5 \\
\hline Skype & 1 & 0,7 \\
\hline Viber & 1 & 0,7 \\
\hline Diğer & 1 & 0,7 \\
\hline Toplam & $\mathbf{1 4 1}$ & $\mathbf{1 0 0}$ \\
\hline
\end{tabular}

Öğrencilerin \%83’ü gündeme düşen bir olayı ilk olarak sosyal medyadan öğrendiklerini belirtmişlerdir. Geleneksel medyanın (Gazete, TV, dergi gibi) çok fazla takip edilmediği görülmektedir (Tablo 3).

Tablo 3. Gündeme Düşen Olayı Ilk Nereden Öğrendikleri

\begin{tabular}{|c|c|c|}
\hline Gündeme Düşen Olayı Illk Nereden & Sayı & $\mathbf{\%}$ \\
\hline Sosyal Medya & 117 & 83,0 \\
\hline Geleneksel Medya & 20 & 14,2 \\
\hline Çevremden & 4 & 2,8 \\
\hline Toplam & 141 & 100 \\
\hline
\end{tabular}

\subsubsection{Sosyal Medya ile İlgili Düşünceleri}

Öğrencilerin sosyal medya ile ilgili düşünceleri Tablo 4'te verilmiştir. Öğrencilerin çoğunluğu Y kuşağında yer almalarının sosyal medyaya çabuk adapte olmalarını sağladığını belirtmişlerdir. Teknolojiyi iyi kullanabilmeleri Y kuşağının temel özelliklerinden biridir. Sosyal medyanın kişisel gelişimleri için önemli olduğu konusunda öğrencilerin \% 46,1'i kararsızdır. Öğrencilerin \% 33,3’ü bu görüşe katılmaktadır. Öğrencilerin \% 50,4’ü sosyal medyayı kullanmadıklarında boşlukta olmadıklarını belirtmişlerdir. Öğrencilerin \% 29,8’i bu konuda kararsızdır. Bu durum öğrencilerin önemli bir kısmının sosyal medya bağımlısı olmadığını göstermektedir.

Tablo 4. Sosyal Medya ile Ilgili Düşünceleri

\begin{tabular}{|l|c|c|c|c|c|c|c|}
\hline \multirow{2}{*}{ Sosyal Medya ile İlgili Düşünceleri } & \multicolumn{2}{|c|}{ Katılıorum } & \multicolumn{2}{c|}{ Kararsızım } & \multicolumn{2}{c|}{ Katılmıyorum } & \multirow{2}{*}{ Ortalama } \\
\cline { 2 - 7 } & Sayı & $\%$ & Sayı & $\%$ & Sayı & $\%$ & \\
\hline $\begin{array}{l}\text { Y kuşağında yer almamın sosyal } \\
\text { medyaya daha çabuk adapte olmamı } \\
\text { sağladığını düşünüyorum. }\end{array}$ & 102 & 72,3 & 26 & 18,4 & 13 & 9,2 & 2,63 \\
\hline $\begin{array}{l}\text { Sosyal medyanın kişisel gelişimim } \\
\text { için önemli olduğunu düşünüyorum. }\end{array}$ & 47 & 33,3 & 65 & 46,1 & 29 & 20,6 & 2,12 \\
\hline $\begin{array}{l}\text { Sosyal medyayı kullanmazsam } \\
\text { kendimi boşlukta hissederim. }\end{array}$ & 28 & 19,9 & 42 & 29,8 & 71 & 50,4 & 1,69 \\
\hline
\end{tabular}




\subsubsection{Sosyal Medyayı Kullanım Alanları}

Öğrencilerin sosyal medyayı kullanım alanları Tablo 5'te verilmiştir. Öğrencilerin sosyal medyayı daha çok bilgi edinme ve bilgi paylaşımı için kullandıkları görülmektedir. Sosyal medyada alanı ile ilgili sayfaları takip edenlerin sayısı daha azdır. Sosyal medyayı resim paylaşmak için kullanmayanların sayısı kullananlardan daha fazladır.

Tablo 5. Sosyal Medyayı Kullanım Alanları

\begin{tabular}{|l|c|c|c|c|c|c|c|}
\hline \multirow{2}{*}{ Sosyal Medya ile ilgili Düşünceleri } & \multicolumn{2}{|c|}{ Katılıyorum } & \multicolumn{2}{c|}{ Kararsızım } & \multicolumn{2}{c|}{ Katılmıyorum } & \multirow{2}{*}{ Ortalama } \\
\cline { 2 - 8 } & Sayı & $\%$ & Sayı & $\%$ & Sayı & $\%$ & \\
\hline $\begin{array}{l}\text { Sosyal medyada alanımla ilgili } \\
\text { sayfaları takip ederim. }\end{array}$ & 62 & 44,0 & 25 & 17,7 & 54 & 38,3 & 2,05 \\
\hline $\begin{array}{l}\text { Sosyal medyayı genelde bilgi edinme } \\
\text { ve bilgi paylaşımı için kullanırım. }\end{array}$ & 69 & 48,9 & 49 & 34,8 & 23 & 16,3 & 2,32 \\
\hline $\begin{array}{l}\text { Sosyal medyayı daha çok resim } \\
\text { paylaşmak için kullanırım. }\end{array}$ & 45 & 31,9 & 38 & 27,0 & 58 & 41,1 & 1,90 \\
\hline
\end{tabular}

3.Katılıyorum 2.Kararsızım 1.Katılmıyorum

\subsection{Kişisel Gelişim ile İlgili Görüşleri}

\subsubsection{Kişisel Gelişimi Arttırmanın Önemi}

Kişisel gelişiminizi arttırmak sizin için neden önemlidir? sorusu sorulmuş ve öğrencilerin birinci sırada verdikleri yanıtlar dikkate alınmıştır. Öğrencilerin \% 53,2'si kendime olan güvenim artar demiştir. İkinci ve üçüncü sırada hedeflerime daha çabuk ulaşırım $(\% 14,2)$ ve dünyaya bakış açım değişir $(13,5)$ yer almaktadır. Öğrencilerin \% 11,3’ü daha mutlu olurum demiştir. Daha fazla para kazanabilirim yanıtını veren öğrencilerin yüzdesi $(\% 7,8)$ azdır (Tablo 6).

Tablo 6. Kişisel Gelişimin Önemi

\begin{tabular}{|l|c|c|}
\hline \multicolumn{1}{|c|}{$\begin{array}{c}\text { Kişisel Gelişiminizi Arttırmak Sizin İçin } \\
\text { Neden Önemlidir? }\end{array}$} & Sayı & $\%$ \\
\hline Kendime olan güvenim artar. & 75 & 53,2 \\
\hline Daha fazla para kazanabilirim. & 11 & 7,8 \\
\hline Dünyaya bakış açım değişir. & 19 & 13,5 \\
\hline Hedeflerime daha çabuk ulaşırım. & 20 & 14,2 \\
\hline Daha mutlu olurum. & 16 & 11,3 \\
\hline Toplam & 141 & 100 \\
\hline
\end{tabular}

Kişisel gelişiminizi arttırmak sizin için neden önemlidir? sorusu ile önemi ile cinsiyet ilişkisi Tablo 7'de verilmiştir. 91 kadın öğrencinin \% 56,04'ü ve 50 erkek öğrencinin \% 48'i “kendime olan güvenim artar" yanıtını vermişlerdir. 
Tablo 7. Kişisel Gelişimin Öneminin Cinsiyete Göre Dağılımı

\begin{tabular}{|c|c|c|c|c|c|}
\hline \multirow{9}{*}{$\begin{array}{l}\text { Kişisel gelişiminizi } \\
\text { artırmak sizin için } \\
\text { neden önemlidir? }\end{array}$} & & \multicolumn{4}{|c|}{ Cinsiyet } \\
\hline & & \multicolumn{2}{|c|}{ Kadın } & \multicolumn{2}{|c|}{ Erkek } \\
\hline & & Sayı & $\%$ & Sayı & $\%$ \\
\hline & $\begin{array}{l}\text { Kendime olan güvenim } \\
\text { artar. }\end{array}$ & 51 & 56,04 & 24 & 48 \\
\hline & $\begin{array}{l}\text { Daha fazla para } \\
\text { kazanabilirim. }\end{array}$ & 8 & 8,79 & 3 & 6 \\
\hline & $\begin{array}{l}\text { Dünyaya bakış açım } \\
\text { değişir. }\end{array}$ & 11 & 12,09 & 8 & 16 \\
\hline & $\begin{array}{l}\text { Hedeflerime daha çabuk } \\
\text { ulaşırım. }\end{array}$ & 10 & 10,99 & 10 & 20 \\
\hline & Daha mutlu olurum. & 11 & 12,09 & 5 & 10 \\
\hline & Toplam & 91 & 100 & 50 & 100 \\
\hline
\end{tabular}

\subsection{2. Üniversite Yaşamının Kişisel Gelişime Katkıları}

Öğrencilerin, üniversite yaşamının kişisel gelişime katkıları hakkındaki düşünceleri Tablo 8'de verilmiştir.

Tablo 8. Üniversite Yaşamının Kişisel Gelişime Katkıları

\begin{tabular}{|l|c|c|c|c|c|c|c|}
\hline \multicolumn{1}{|c|}{$\begin{array}{c}\text { Üniversite Yaşamının Kişisel Gelişime } \\
\text { Katkıları }\end{array}$} & \multicolumn{2}{|c|}{ Katılıyorum } & \multicolumn{2}{c|}{ Kararsızım } & \multicolumn{2}{c|}{ Katılmıgorum } & \multirow{2}{*}{ Ortalama } \\
\cline { 2 - 8 } & Sayı & $\%$ & Sayı & $\%$ & Sayı & $\%$ & \\
\hline $\begin{array}{l}\text { Üniversite yaşamımın kişisel gelişimime } \\
\text { önemli katkılar sağladığını düşünüyo- } \\
\text { rum. }\end{array}$ & 113 & 80,1 & 17 & 12,1 & 11 & 7,8 & 2,72 \\
\hline $\begin{array}{l}\text { Bozüyük'ün Eskişehir ve Bilecik'e yakın } \\
\text { olması kişisel gelişimimi olumlu } \\
\text { etkilediğini düşünüyorum }\end{array}$ & 68 & 48,2 & 39 & 27,7 & 34 & 24,1 & 2,24 \\
\hline $\begin{array}{l}\text { Bozüyük'te katılabileceğim sosyal } \\
\text { etkinlikler yapıldığını düşünüyorum. }\end{array}$ & 23 & 16,3 & 39 & 27,7 & 79 & 56,0 & 1,60 \\
\hline
\end{tabular}

3.Katılıyorum 2.Kararsızım 1.Katılmıyorum

Öğrenciler ağırlıklı olarak üniversite yaşamının kişisel gelişimlerine önemli katkılar sağladığını belirtmişlerdir. Yüksekokul, Bilecik iline bağlı Bozüyük ilçesinde yer almaktadır. Bozüyük'ün Eskişehir ve Bilecik'e yakın olmasının kişisel gelişimlerini olumlu etkilediğini düşünmektedirler. Ancak Bozüyük’te katılabilecekleri sosyal etkinliklerin olmadığını belirtmişlerdir.

\subsubsection{Muhasebe ve Denetim Bölümü’nün Kişisel Gelişime Katkıları}

Öğrenciler genelde okulda düzenlenen mesleki seminerlerin kişisel gelişimlerine katkıda bulunduğunu düşünmektedirler. Ancak kararsız olan ve katılmayan öğrencilerde bulunmaktadır. Okudukları bölümün sayısal yönde gelişimlerine ve analitik yönde düşünmelerine önemli katkılar sağladığını düşünmektedirler. Okuduğu bölümdeki dersler uygulama ağılıklı olduğu için çalışma hayatına daha çabuk uyum sağlayacağını ve okulda yapılan grup çalışmaları, araştırmalar ve 
sunumların kişisel gelişimlerine önemli katkılar sağladığını düşünmektedirler. Ancak belirtilen görüşlere katılmayan ve kararsız olan öğrenciler de bulunmaktadır (Tablo 9).

Tablo 9. Bölümün Kişisel Gelişime Katkıları

\begin{tabular}{|c|c|c|c|c|c|c|c|}
\hline & \multicolumn{2}{|c|}{ Katılıyorum } & \multicolumn{2}{|c|}{ Kararsızım } & \multicolumn{2}{|c|}{ Katılmıyorum } & \multirow{2}{*}{ Ortalama } \\
\hline & Sayı & $\%$ & Sayı & $\%$ & Sayı & $\%$ & \\
\hline $\begin{array}{l}\text { Okuduğum bölümün sayısal yönde } \\
\text { gelişsimime ve analitik yönde düşünmeme } \\
\text { önemli katkılar sağladığını düşünüyorum. }\end{array}$ & 66 & 46,8 & 48 & 34,0 & 27 & 19,1 & 2,27 \\
\hline $\begin{array}{l}\text { Okuduğum bölümdeki dersler uygulama } \\
\text { ağıılıklı olduğu için çalışma hayatıma daha } \\
\text { çabuk uyum sağlayacağını düşünüyorum. }\end{array}$ & 63 & 44,7 & 44 & 31,2 & 34 & 24,1 & 2,20 \\
\hline 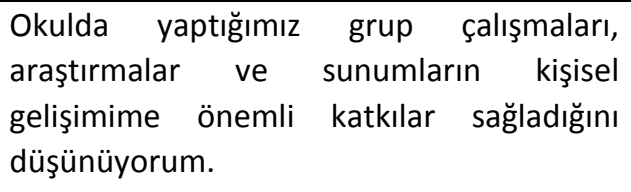 & 79 & 56,0 & 39 & 27,7 & 23 & 16,3 & 2,39 \\
\hline $\begin{array}{lcc}\text { Okulumuzda } & \text { düzenlenen } & \text { mesleki } \\
\text { seminerlerin kişisel gelişimime } & \text { önemli } \\
\text { katkılar sağladığını düşünüyorum. } & \end{array}$ & 89 & 63,1 & 33 & 23,4 & 19 & 13,5 & 2,49 \\
\hline
\end{tabular}

3.Katılıyorum 2.Kararsızım 1.Katılmıyorum

\subsubsection{Kişisel Gelişim İle İlgili Çabaları}

Öğrencilerin kişisel gelişim ile ilgili çabaları Tablo 10'da verilmiştir. Öğrenciler kitap okumanın kişisel gelişim için çok önemli olduğunu düşünmektedirler. İnternet'i alanları ile ilgili araştırma yaparken yoğun bir şekilde kullandıklarını belirtmişlerdir. Bilgisayar teknolojisini ve programları etkin olarak kullanabilmektedirler. Genelde sosyal sorumluluk kapsamında etkinliklere katılmaktadırlar. Öğrencilerin \%50'si alan ile ilgili güncel gelişmeleri takip etmekte, yabancı dillerini geliştirmek için çabalamaktadır. Öğrencilerin yaklaşık \% 50'si kişisel gelişimle ilgili kitaplar okumaktadır. Ancak muhasebe mesleğini ilgilendiren sempozyum, panel gibi etkinlikleri ve dergileri yakından takip edenlerin sayısı azdır. 
Tablo 10. Kişisel Gelişim Ile IIgili Çabaları

\begin{tabular}{|c|c|c|c|c|c|c|c|}
\hline \multirow{2}{*}{ Kişisel Gelişim İle İlgili Çabaları } & \multicolumn{2}{|c|}{ Katılıyorum } & \multicolumn{2}{|c|}{ Kararsızım } & \multicolumn{2}{|c|}{ Katılmıyorum } & \multirow{2}{*}{ Ortalama } \\
\hline & Sayı & $\%$ & Sayı & $\%$ & Sayı & $\%$ & \\
\hline $\begin{array}{l}\text { Sosyal sorumluluk kapsamında etkinliklere } \\
\text { katılırım. }\end{array}$ & 94 & 66,7 & 27 & 19,1 & 20 & 14,2 & 2,52 \\
\hline $\begin{array}{l}\text { Alanımla ilgili teknolojik ve güncel gelişmeleri } \\
\text { takip ederim. }\end{array}$ & 70 & 49,6 & 44 & 31,2 & 27 & 19,1 & 2,30 \\
\hline $\begin{array}{l}\text { Alanımla ilgili konularda araştırma yaparken } \\
\text { İnternet'i etkin olarak kullanırım. }\end{array}$ & 118 & 83,7 & 15 & 10,6 & 8 & 5,7 & 2,78 \\
\hline $\begin{array}{l}\text { Bilgisayar teknolojisini ve programlarını etkin } \\
\text { olarak kullanabildiğimi düşünüyorum. }\end{array}$ & 88 & 62,4 & 44 & 31,2 & 9 & 6,4 & 2,56 \\
\hline Yabancı dilimi geliştirmek için çabalıyorum. & 70 & 49,6 & 40 & 28,4 & 31 & 22,0 & 2,27 \\
\hline $\begin{array}{l}\text { Muhasebe mesleğini ilgilendiren sempozyum, } \\
\text { panel gibi etkinlikleri ve dergileri yakından } \\
\text { takip ederim. }\end{array}$ & 29 & 20,6 & 55 & 39,0 & 57 & 40,4 & 1,80 \\
\hline $\begin{array}{l}\text { Kitap okumanın kişisel gelişim için çok önemli } \\
\text { olduğunu düşünüyorum. }\end{array}$ & 124 & 87,9 & 11 & 7,8 & 6 & 4,3 & 2,83 \\
\hline Kişisel gelişimle ilgili kitaplar okurum. & 67 & 47,5 & 44 & 31,2 & 30 & 21,3 & 2,26 \\
\hline
\end{tabular}

3.Katılıyorum 2.Kararsızım 1.Katılmıyorum

\section{Sonuç}

Uygulamalı Bilimler Yüksekokulu, Muhasebe ve Denetim Bölümü öğrencilerinin sosyal medya ve kişisel gelişim ile ilgili görüşlerini ve çabalarını ortaya koymak amacıyla yapılan bu çalışmada öğrencilerin çoğunun sosyal medya hesabı olarak ilk sırada Instagram'ı kullandıkları ve sosyal medyada iletişimi Whatsapp ile kurdukları görülmektedir. Gündeme düşen bir olayı ilk olarak sosyal medyadan öğrenmektedirler. Geleneksel medyayı çok fazla takip etmemektedirler.

Öğrencilerin çoğunluğu Y kuşağında yer almalarının sosyal medyaya çabuk adapte olmalarını sağladığını belirtmişlerdir. Öğrenciler genelde sosyal medyayı kullanmadıklarında kendilerini boşlukta hissetmemektedirler. Bu durum sosyal medya bağımlısı olmadıklarını göstermektedir. Öğrenciler genelde sosyal medyayı bilgi edinmek için kullanmaktadırlar. Alanları ile ilgili sayfaları çok fazla takip etmemektedirler. Sosyal medyanın kişisel gelişimleri için önemli olduğunu düşünenlerin sayısı az kararsız olanların sayısı daha fazladır.

Öğrenciler ağırlıklı olarak üniversite yaşamının kişisel gelişimlerine önemli katkılar sağladığını belirtmişlerdir. Öğrenciler kişisel gelişimlerini arttırmanın öncelikle kendilerine olan güveni arttıracağını düşünmektedirler. Daha fazla para kazanabilirim yanıtını veren öğrencilerin yüzdesi çok azdır.

Öğrenciler genelde okulda katıldıkları mesleki seminerlerin kişisel gelişimlerine katkıda bulunduğunu düşünmektedirler. Ancak kararsız olan ve katılmayan öğrencilerde bulunmaktadır. Okudukları bölümün sayısal yönde gelişimlerine ve analitik yönde düşünmelerine önemli katkılar 
sağladığını düşünmektedirler. Dersler uygulama ağırlıklı olduğu için çalışma hayatına daha çabuk uyum sağlayacaklarını ve okulda yapılan grup çalışmaları, araştırmalar ve sunumların kişisel gelişimlerine önemli katkılar sağladığını düşünmektedirler. Ancak belirtilen görüşlere katılmayan ve kararsız olan öğrenciler de bulunmaktadır

Kişisel gelişimlerini artırmak için çabaladıkları görülmektedir. Internet'i alanları ile ilgili araştırma yaparken kullanmaktadırlar. Bilgi teknolojisini etkin kullanmaktadırlar. Genelde sosyal sorumluluk ile ilgili etkinliklere katılmaktadırlar. Öğrencilerin \%50'si alan ile ilgili güncel gelişmeleri takip etmekte, yabancı dillerini geliştirmek için çabalamaktadır. Öğrenciler kitap okumanın kişisel gelişim için çok önemli olduğunu düşünmektedirler. Öğrencilerin yaklaşık \% 50'si kişisel gelişimle ilgili kitaplar okumaktadır. Ancak muhasebe mesleğini ilgilendiren sempozyum, panel gibi etkinlikleri ve dergileri çok fazla takip etmemektedirler.

\section{Kaynakça}

Altunışık, Remzi, Recai Coşkun, Serkan Bayraktaroğlu, Engin Yıldırım (2005), Sosyal Bilimlerde Araştırma Yöntemleri - SPSS Uygulamal, Sakarya Yayınc1lık.

Balaban, Özlem ve Dilek Çakmak (2016), "Üniversite Öğrencilerinin Kişisel Gelişim Eğitimlerine Yönelik Algılarının İncelenmesi”, Sakarya İktisat Dergisi, Cilt: 5, Sayı: 1, s. 1-17.

Başoğlu, Umut Davut ve Şenol Yanar (2017), “Üniversite Öğrencilerinin Sosyal Medya Kullanım Amaçları ve Alışkanlıklarının Belirlenmesi”, Kilis 7 Aralık Üniversitesi Beden Eğitimi ve Spor Bilimleri Dergisi, 1(2), 6-13.

Eymen, U. Erman (2007), SPSS 15 Veri Analiz Yöntemleri, İstatistik Merkezi Yayın No: 1.

Kamiloğlu, Fatma ve Özge U. Yurttaş (2014), "Sosyal Medyanın Bilgi Edinme ve Kişisel Gelişim Sürecine Katkısı ve Lise Öğrencileri Üzerine Bir Alan Çalışmasıı", İleti-ş-im, 21, 129-150.

Kurnaz, Niyazi ve Yusuf Gümüş (2010), "Muhasebe Bölümü Öğrencilerinin Muhasebe Mesleği İle İlgili Etik Dışı Davranışlara İlişskin Algı Analizi: Dumlupınar Üniversitesi Uygulamalı Bilimler Yüksekokulu Örneği”, Muhasebe ve Finansman Dergisi, Say1 46, Nisan, s. 157-174.

Vural Akıncı, Z. Beril ve Mikail Bat (2010), "Yeni Bir İletişim Ortamı Olarak Sosyal Medya: Ege Üniversitesi İletişim Fakültesine Yönelik Bir Araştırma”, Yaşar Üniversitesi Dergisi, 20 (5), 3348-3383. 